\title{
Non-Reason Code
}

National Cancer Institute

\section{Source}

National Cancer Institute. Non-Reason Code. NCI Thesaurus. Code C104441.

A coded value specifying that an expected reason for something occurring was not the motivation, cause or rationale in this particular case. 